\title{
Cardiotoxicity of the Anticancer Therapeutic Agent Bortezomib
}

Dominika Nowis, ${ }^{*}$ Michał Mączewski, ${ }^{\dagger}$ Urszula Mackiewicz, ${ }^{\dagger}$ Marek Kujawa, ${ }^{\ddagger}$ Anna Ratajska, ${ }^{\S}$ Mariusz R. Wieckowski, ${ }^{\text {TI }}$ Grzegorz M. Wilczyński," Monika Malinowska," Jacek Bil, ${ }^{*}$ Paweł Salwa, ${ }^{*}$ Marek Bugajski, ${ }^{*}$ Cezary Wójcik, ${ }^{* *}$ Maciej Siński, ${ }^{\dagger \dagger}$ Piotr Abramczyk, ${ }^{\text {t† }}$ Magdalena Winiarska, ${ }^{*}$ Anna Dąbrowska-Iwanicka, ${ }^{\ddagger \neq}$ Jerzy Duszyński, ${ }^{\text {"ा }}$ Marek Jakóbisiak, ${ }^{*}$ and Jakub Golab§§

From the Departments of Immunology," Histology and Embryology, ${ }^{\ddagger}$ and Pathology, ${ }^{\S}$ Center of Biostructure Research, Medical University of Warsaw, Warsaw, Poland; the Department of Clinical Physiology, ${ }^{\dagger}$ Postgraduate Medical School, Warsaw, Poland; the Laboratories of Bioenergetics and Biomembranes, ${ }^{\pi}$ and Molecular and Systemic Neuromorphology," Nencki Institute of Experimental Biology, Warsaw, Poland; the Department of Anatomy and Cell Biology,* Indiana University School of Medicine-Evansville, Evansville, Indiana; the Departments of Internal Diseases, Hypertension, and Vascular Disease, ${ }^{\text {tt }}$ Medical University of Warsaw, Warsaw, Poland; the Department of Lymphoproliferative Disease, ${ }^{\#}$ Maria Sklodowska-Curie Memorial Cancer Center, Institute of Oncology, Warsaw, Poland; and the Institute of Physical Chemistry, ${ }^{\text {SS }}$ Polish Academy of Sciences, Warsaw, Poland

Recent case reports provided alarming signals that treatment with bortezomib might be associated with cardiac events. In all reported cases, patients experiencing cardiac problems were previously or concomitantly treated with other chemotherapeutics including cardiotoxic anthracyclines. Therefore, it is difficult to distinguish which components of the therapeutic regimens contribute to cardiotoxicity. Here, we addressed the influence of bortezomib on cardiac function in rats that were not treated with other drugs. Rats were treated with bortezomib at a dose of $0.2 \mathrm{mg} / \mathrm{kg}$ thrice weekly. Echocardiography, histopathology, and electron microscopy were used to evaluate cardiac function and structural changes. Respiration of the rat heart mitochondria was measured polarographically. Cell culture experiments were used to determine the influence of bortezomib on cardiomyocyte survival, contractility, $\mathrm{Ca}^{2+}$ fluxes, induction of endoplasmic reticulum stress, and autophagy. Our findings indicate that bortezomib treatment leads to left ventricular contractile dysfunction manifested by a significant drop in left ventricle ejection fraction. Dramatic ultrastructural abnormalities of cardiomyocytes, especially within mitochondria, were accompanied by decreased ATP synthesis and decreased cardiomyocyte contractility. Monitoring of cardiac function in bortezomib-treated patients should be implemented to evaluate how frequently cardiotoxicity develops especially in patients with pre-existing cardiac conditions, as well as when using additional cardiotoxic drugs. (Am J Pathol 2010, 176:2658-2668; DOI: 10.2353/ajpath.2010.090690)

The use of novel drugs targeting vital cellular pathways in tumor cells has markedly improved the treatment outcomes for neoplastic diseases. Particularly good results have been achieved in the management of hematological malignancies with drugs such as Bcr-Abl antagonists, monoclonal antibodies, and proteasome inhibitors. These successes translate into rising numbers of long-term surviving patients, but paradoxically they also increase the significance of accompanying diseases, including complications of cancer treatments. Clinical reports have documented unexpected cardiotoxicity associated with the use of novel drugs such as herceptin, imatinib, sunitinib, or sorafenib. ${ }^{1-4}$ Side effects of treatment with a reversible proteasome inhibitor, bortezomib, are mainly associated

Supported by grants from the Ministry of Science and Higher Education in Poland [N401 324033 to D.N., N301 092 32/3407 to M.W., and N40112331/2736 to J.G], the Medical University of Warsaw [1M19/N and $1 \mathrm{M} 19 / \mathrm{WB} 1 / 07$ to M.J.], and an institutional appropriation of the American Cancer Society grant [IRG-84-002-22 to C.W.]. M.W., is also supported by the Polish Mitochondrial Network. J.G., J.B., and M.B. are recipients of the Mistrz Award from the Foundation for Polish Science. M.W. is a recipient of the START Award from the Foundation for Polish Science.

Accepted for publication February 18, 2010.

Supplemental material for this article can be found on http://ajp. amjpathol.org

Address reprint requests to Jakub Golab, M.D., Ph.D., Department of Immunology, Center of Biostructure Research, Medical University of Warsaw, 1A Banacha Str., F Building, 02-097 Warsaw, Poland. E-mail: jakub. golab@wum. edu.pl. 
with neurological complications (peripheral neuropathy) ${ }^{5,6}$ Recent case reports provide alarming signals that treatment with bortezomib might be associated with cardiac events..$^{7-9}$ In all reported cases, patients experiencing cardiac problems were previously or concomitantly treated with other chemotherapeutics including cardiotoxic anthracyclines. Therefore, it is difficult to distinguish which components of the therapeutic regimens contribute to cardiotoxicity. Here, we addressed the influence of bortezomib on cardiac function in rats that were not treated with other drugs. Our findings indicate that bortezomib treatment leads to impaired cardiac function associated with dramatic ultrastructural abnormalities of cardiomyocytes, especially within mitochondria.

\section{Materials and Methods}

\section{Cell Lines and Reagents}

Rat cardiomyoblastic (H9c2), human colorectal carcinoma (SW480), human breast cancer (MDA-MB 231), and human ovarian carcinoma (MDAH2774) cell lines were purchased from ATCC (Manassas, VA). Cells were cultured in Dulbecco's modified Eagle's medium supplemented with $10 \%$ heat-inactivated fetal calf serum, antibiotics, 2-mercaptoethanol (50 mmol/L), and L-glutamine (2 mmol/L) (all from Invitrogen, Carlsbad, CA). MG132, epoxomycin, carbobenzoxyl-Ile-Glu-(O-t-butyl)-Ala-Leucinal (PSI), and tunicamycin were purchased from Calbiochem/EMD (San Diego, CA), and were dissolved in dimethyl sulfoxide. Imatinib mesylate was from Novartis Pharma AG (Basel, Switzerland) and was dissolved in dimethyl sulfoxide. Bortezomib (Millenium Pharmaceuticals, Cambrigde, $\mathrm{MA}$ ) was dissolved in $0.9 \% \mathrm{NaCl}$.

\section{Animals and Treatment}

Male Wistar rats (250 to $350 \mathrm{~g}$ ) were used in the experiments. Breeding pairs were obtained from the Animal House of the Polish Academy of Sciences Medical Research Center (Warsaw, Poland). All in vivo experiments were performed in accordance with the guidelines approved by the Ethical Committee of the Medical University of Warsaw, based on national laws that are in full agreement with the European Union directive and US National Institutes of Health guidelines on animal experimentation. Rats were injected i.p. with $0.2 \mathrm{mg} / \mathrm{kg}$ of bortezomib three times a week for 1 to 3 weeks. Wash-out indicates time after treatment termination.

\section{Echocardiography}

Echocardiography was performed using MyLab25 (Esaote, Italy) with a $13 \mathrm{MHz}$ linear array transducer. Each rat was examined at baseline, 24 hours, 3 days, 7 days, 14 days, and 21 days after treatment initialization, and 1 week and 3 weeks after termination of treatment (wash-out). Under light anesthesia (i.p. ketamine $\mathrm{HCl}$ and xylazine, 75 and 3.5 $\mathrm{mg} / \mathrm{kg}$ body weight, respectively,) left ventricular (LV) enddiastolic and end-systolic diameters were determined from the short-axis view at the midpapillary level and fractional shortening was calculated as (LV diastolic - LV systolic diameter)/LV diastolic diameter. LV end-diastolic and endsystolic areas were planimetered from the parasternal longaxis view. LV ejection fraction was calculated as (LV diastolic area - LV systolic area)/LV diastolic area.

\section{Immunofluorescence Microscopy}

For immunofluorescence microscopy H9c2 cells were dispensed in 8-well chamber slides (Nunc, Roskilde, Denmark) and cultured with $10 \mathrm{nmol} / \mathrm{L}$ bortezomib for 24 hours. Then, the cells were washed with PBS, slides were methanol-fixed for 30 minutes at $-20^{\circ} \mathrm{C}$, blocked with $5 \%$ normal donkey serum and incubated overnight at $4{ }^{\circ} \mathrm{C}$ with primary anti-ubiquitin FK2 antibody (Assay Designs, Ann Arbor, MI) in 5\% normal donkey serum in PBS. Slides were washed thrice in PBS and incubated with donkey anti-mouse Alexa555-conjugated antibody (Invitrogen; 1:200 for 2 hours at room temperature). The slides were washed, mounted in 4,6-diamidino-2-phenylindole-enriched Vectashield medium (Vector Laboratories, Burlingame, CA), and observed under fluorescence confocal microscope (Leica TCS SP2).

\section{Transient Transfection of H9c2 Cells with LC3-Encoding Plasmid}

pEGFP-LC3m plasmid encoding rat LC3 gene cloned into a green fluorescent protein (GFP) fusion protein expression vector was a generous gift from Prof. Noboru Mizushima and Dr. Tamotsu Yoshimori and has been described. ${ }^{10} \mathrm{H} 9 \mathrm{c} 2$ cells were seeded into 2-well chamber slides (Nunc) at $1 \times 10^{5}$ cells per well. After 24 hours, the cells were transfected with pEGFP-LC3m plasmid using a standard LipofectAMINE2000 protocol (Invitrogen). Six hours post-transfection, growth medium supplemented with $10 \mathrm{nmol} / \mathrm{L}$ bortezomib was added after removal of transfection mixture. Cells were washed with PBS 48 hours later, and slides were methanol-fixed for 30 minutes at $-20^{\circ} \mathrm{C}$, blocked with $5 \%$ normal donkey serum, and incubated for 2 hours at room temperature with primary monoclonal anti-GFP antibody (Convance, Emeryville, CA) in 5\% normal donkey serum in PBS. Slides were washed thrice in PBS and incubated with donkey anti-mouse Alexa488-conjugated antibody (Invitrogen, 1:200 for 1 hour at room temperature). The slides were washed, stained with TO-PRO (Invitrogen, 1:3000, 15 minutes at room temperature), mounted in Vectashield (Vector Laboratories), and observed under a fluorescence confocal microscope (Leica TCS SP2).

\section{Histopathology}

The morphological studies were performed in Wistar rats (250 to 350 g). Rats received i.p. injections of bortezomib at the dose of $0.2 \mathrm{mg} / \mathrm{kg}$ for 7 days (total three injections) or for 3 weeks (total nine injections). Control rats were injected with the diluent (0.9\% saline). Rats were anes- 
thetized with i.p. injection of a lethal dose of pentobarbital/pentobarbital nitrite solution $(7 \mathrm{mg}$ and $35 \mathrm{mg}$ per rat, respectively), the aorta was cannulated, and pre-warmed PBS containing $12 \mathrm{lU} / \mathrm{ml}$ heparin was injected through the cannula followed by injection of $2 \%$ paraformaldehyde in PBS. The hearts were excised, cut transversally into four rings, and immersed in buffered $4 \%$ paraformaldehyde for subsequent 12 hours. After washing in distilled water, the hearts were dehydrated in increasing concentrations of ethanol, cleared in xylene, and embedded in paraffin. Paraffin sections were deparaffinized on a hot plate, followed by three changes of xylene and three changes of ethanol and stained with H\&E or Picrosirius red. Sections were analyzed on a Nikon Labophot light microscope equipped with a digital camera.

\section{Transmission Electron Microscopy}

For transmission electron microscopy (TEM), Wistar rats (treated with bortezomib for 1 or 3 weeks) or C57BL/6 mice (treated with bortezomib for 3 weeks) and control animals were perfused transcardially with $3 \%$ glutaraldehyde in $0.1 \mathrm{~mol} / \mathrm{L}$ cacodylate buffer. For TEM studies in H9c2 cells, $1 \times 10^{6}$ of control cells or cells incubated for 48 hours with $10 \mathrm{nmol} / \mathrm{L}$ bortezomib were trypsinized, washed with ice-cold PBS, and suspended in $3 \%$ glutaraldehyde in $0.1 \mathrm{~mol} / \mathrm{L}$ cacodylate buffer. Fragments of heart left ventricle or cell pellets were postfixed with $1 \%$ $\mathrm{OsO}_{4}$ in the cacodylate buffer, and then dehydrated in increasing concentrations of ethanol and propylene oxide and embedded in Poly/Bed 812 (Polysciences, Inc., Warrington, PA). Resin blocks were cut with a diamond knife on an RMC type MTXL ultramicrotome. Ultrathin sections were mounted on Formvar carbon-coated grids, stained with lead citrate and uranyl acetate, and observed in a Jeol JEM-100S transmission electron microscope (Jeol, Tokyo, Japan).

\section{Isolation of Rat Heart Mitochondria and Evaluation of Mitochondrial Respiration}

Heart mitochondria were prepared from 250 to $350 \mathrm{~g}$ male Wistar rats, as described by Schaller et $\mathrm{al}^{11}$ using the trypsin-digestion procedure. In brief, pieces of minced hearts were trypsinized (1 mg trypsin/heart) for 20 minutes in $180 \mathrm{mmol} / \mathrm{L} \mathrm{KCl}, 25 \mathrm{mmol} / \mathrm{L} \mathrm{Tris} / \mathrm{HCl}, 10$ mmol/L EDTA ( $\mathrm{pH}$ 7.4) under gentle agitation in an ice bath. Next, the material was mixed with the same buffer containing albumin and Complete protease inhibitors cocktail (Roche Diagnostics, Mannheim, Germany). Trypsinized hearts were then gently homogenized at $4^{\circ} \mathrm{C}$, debris, undisturbed cells and nuclear fraction were removed by centrifugation at $350 \times g$ for 3 minutes, and mitochondria were sedimented at $2500 \times g$ for 10 minutes and washed in $180 \mathrm{mmol} / \mathrm{L} \mathrm{KCl}$ without EDTA and albumin. Only mitochondrial preparations with mostly intact outer membranes were used. Protein concentration in the mitochondrial fraction was determined according to Bradford's method using Bio-Rad Protein Assay (BioRad). Respiration of the rat heart mitochondria was mea- sured polarographically using a Clark oxygen electrode (Yellow Springs Instruments, Yellow Springs, $\mathrm{OH}$ ) in a thermostatic water-jacketed vessel at $25^{\circ} \mathrm{C}$. The respiratory buffer contained $180 \mathrm{mmol} / \mathrm{L} \mathrm{KCl,} 25 \mathrm{mmol} / \mathrm{L}$ Tris/ $\mathrm{HCl}$, and $0.5 \mathrm{mmol} / \mathrm{L}$ EGTA (pH 7.4). Total volume was $1.0 \mathrm{ml}$ and the amount of mitochondria was $1 \mathrm{mg}$. Respiratory substrates were used at the following concentrations: $5 \mathrm{mmol} / \mathrm{L}$ glutamate, $5 \mathrm{mmol} / \mathrm{L}$ malate, $5 \mathrm{mmol} / \mathrm{L}$ succinate, $2 \mathrm{mmol} / \mathrm{L}$ ascorbate, $100 \mu \mathrm{mol} / \mathrm{L}$ tetramethylphenylenediamine (TMPD). The concentration of oligomycin and carbonyl cyanide 3-chlorophenylhydrazone (CCCP), when added, was $1 \mu \mathrm{g} / \mathrm{ml}$ and $1 \mu \mathrm{mol} / \mathrm{L}$, respectively. To determine respiration under state III (the capability of ATP production by mitochondria), $2 \mathrm{mmol} / \mathrm{L}$ solution of ADP was added to the suspension of mitochondria and oxygen consumption was measured polarographically as described above.

\section{Cytotoxic/Cytostatic Assays}

The cytostatic/cytotoxic effects in H9c2 and cancer cell lines were measured using crystal violet staining as described. ${ }^{12}$ Briefly, tumor cells were dispensed into 96well plates (Sarstedt, Numbrecht, Germany) at $3 \times 10^{3}$ cells per well and allowed to attach overnight. The following day the investigated agents were added at indicated concentrations. After incubation the cells were rinsed with PBS and stained with $0.5 \%$ crystal violet in $2 \%$ ethanol for 10 minutes at room temperature. Plates were washed four times with tap water and cells were lysed with $1 \%$ SDS solution. Absorbance was measured at 595 $\mathrm{nm}$ using an enzyme-linked immunosorbent assay reader (Bio-Rad, Hercules, CA). Cryopreserved ready-to-use contractile neonatal ventricular rat cardiomyocytes ( $\mathrm{P} 1-2)$ were purchased from Lonza (Walkersville, MD) and seeded into 96-well plate in Clonetics Rat Cardiac Myocyte Basal Medium supplemented with Clonetics SingleQuots, 10\% horse serum, 10\% fetal bovine serum, and antibiotics/ antimycotics mixture (all from Lonza), according to the manufacturer's protocol. The wells were previously coated with nitrocellulose (BioRad) dissolved in methanol and left for 10 minutes to evaporate alcohol. The medium was replaced with the fresh one containing tested drugs 4 hours post-seeding and supplemented with $200 \mu \mathrm{mol} / \mathrm{L}$ 5-bromo-2'-deoxyuridine (Sigma) to prevent proliferation of non-cardiomyocyte cells. After 24 hours of incubation with drugs $50 \mu \mathrm{g}$ of 2,3-bis (2-methoxy-4-nitro-5-sulfophenyl)-5[(phenylamino)carbonyl]-2H-tetrazolium hydroxide (XTT) and $0.38 \mu \mathrm{g}$ of phenazine methosulfate (all from Sigma) per well were added for a 24-hour co-incubation. Next, the absorbance was measured at the wavelength of $450 \mathrm{~nm}$. Cytotoxicity was expressed as relative viability of cells (\% of control cultures incubated with medium only) and was calculated as follows: relative viability $=(\mathrm{Ae}-$ $A b) \times 100 /(A c-A b)$, where $A b$ is the background absorbance, Ae is experimental absorbance, and Ac is the absorbance of untreated controls. Series (at least three) of independent experiments were performed and the results presented are representative. 


\section{Experiments in Mice}

Female C57BL/6 mice 8 to 12 weeks old and were used in the experiments. Breeding pairs were obtained from the Animal House of the Polish Academy of Sciences Medical Research Center (Warsaw, Poland). All in vivo experiments were performed in accordance with the guidelines approved by the Ethical Committee of the Medical University of Warsaw, based on national laws that are in full agreement with the European Union directive on animal experimentation. Mice were treated with i.p. injections of bortezomib at a dose of $1 \mathrm{mg} / \mathrm{kg}$ three times a week for 3 weeks.

\section{Isolation, Superfusion, and Culture of Adult Rat Cardiomyocytes}

Cells were isolated as described previously, with some modifications. ${ }^{13}$ After perfusion of the heart with Tyrode solution containing collagenase (Boehringer, Ingelheim, Germany) and protease (Sigma), right ventricle was separated and discarded. For $\mathrm{Ca}^{2+}$ transient and cell shortening recordings, myocytes of the LV tissue were resuspended in Tyrode solution, (144 mmol/L NaCl, $5 \mathrm{mmol} / \mathrm{L}$ $\mathrm{KCl}, 1 \mathrm{mmol} / \mathrm{L} \mathrm{MgCl} 2,0.43 \mathrm{mmol} / \mathrm{L} \mathrm{NaH}_{2} \mathrm{PO}_{4}, 10 \mathrm{mmol} / \mathrm{L}$ $\mathrm{N}$-2-hydroxyethylpiperazine- $N^{\prime}$-2-ethanesufonic acid, $11 \mathrm{mmol} / \mathrm{L}$ glucose) placed in a superfusion chamber mounted on the stage of an inverted microscope (Nikon), and superfused with Tyrode solution containing $2 \mathrm{mmol} / \mathrm{L}$ $\mathrm{Ca}^{2+}$ at $37^{\circ} \mathrm{C}$.

For cell culture, myocytes of LV tissue were resuspended in the myocyte plating medium, containing modified Eagle's medium with Hank's balanced salt solution supplemented with 10\% fetal bovine serum (Hyclone, Logan, UT), $100 \mathrm{U} / \mathrm{ml}$ penicillin-G (Sigma), $10 \mathrm{mmol} / \mathrm{L}$ butanedione monoxime (BDM) (Sigma), and $2 \mathrm{mmol} / \mathrm{L}$ L-glutamine (Sigma), and plated into 96-well plates freshly coated with $10 \mu \mathrm{g} / \mathrm{ml}$ laminin (BD Biosciences, Bedford, MA). One hour post-plating, the plating medium was replaced with culture medium composed of modified Eagle's medium with Hanks balanced salt solution supplemented with 10\% fetal bovine serum (Hyclone), $0.1 \%$ bovine serum albumin (Sigma), ITS medium supplement (insulin, transferrin, selenium; Sigma), $100 \mathrm{U} / \mathrm{ml}$ penicillin-G (Sigma), $10 \mathrm{mmol} / \mathrm{L}$ butanedione monoxime (BDM) (Sigma), $2 \mathrm{mmol} / \mathrm{L}$ L-glutamine (Sigma), and supplemented with bortezomib. After 24 or 48 hours of treatment, the cytostatic/cytotoxic effects were tested in a standard 3-(4,5-dimethylthiazol-2-yl)-2,5-diphenyltetrazolium bromide assay.

\section{$\mathrm{Ca}^{2+}$ Transient, Cell Shortening, and $\mathrm{Ca}^{2+}$ Transport by SERCA2a and NCX}

The LV myocytes were incubated for 15 minutes with 10 $\mu \mathrm{mol} / \mathrm{L}$ Indo-1 acetoxymethyl ester as described. ${ }^{14}$ The ratio of Indo-1 fluorescence at 405 and $495 \mathrm{~nm}$ for the diastolic and systolic $\mathrm{Ca}^{2+}$ concentration was measured on a Dual Channel Ratio Fluorometer (Biomedical Instrumentation Group, University of Pennsylvania, PA). The difference between the systolic and diastolic Indo-1 ratios was used as a measure of the amplitude of $\mathrm{Ca}^{2+}$ transients. The rate constant $(r)$ of monoexponential curve (described by equation: $y=A e^{-x r}$ ) fitted to the decaying part of $\mathrm{Ca}^{2+}$ transient was taken as an index of the rate of $\mathrm{Ca}^{2+}$ transient decay. Cell shortening was recorded with a video edge detector (Cardiovascular Laboratories, School of Medicine, UCLA). $\mathrm{Ca}^{2+}$ transport by sarcoplasmic reticulum $\mathrm{Ca}^{2+}$-ATP-ase (SERCA2a) and $\mathrm{Na}^{+} / \mathrm{Ca}^{2+}$ exchanger $\mathrm{NCX}$ was estimated from the rate constants $(r$ ) of single exponential curves fitted to the decaying part of electrically evoked and caffeine-evoked $\mathrm{Ca}^{2+}$ transients according to Choi and Eisner. ${ }^{15}$ The rate constant of decay of electrically evoked $\mathrm{Ca}^{2+}$ transients (r) reflects the rate of combined $\mathrm{Ca}^{2+}$ transport executed mainly by SERCA2a, which pumps $\mathrm{Ca}^{2+}$ back to sarcoplasmic reticulum, and by NCX, which extrudes $\mathrm{Ca}^{2+}$ out of the cell. $\mathrm{Ca}^{2+}$ transport by sarcolemmal $\mathrm{Ca}^{2+}$ ATP-ase and mitochondrial uptake are of minor importance. Caffeine releases $\mathrm{Ca}^{2+}$ from the sarcoplasmic reticulum and prevents its reaccumulation in sarcoplasmic reticulum $\left(\mathrm{Ca}^{2+}\right.$ transport by SERCA2a under caffeine perfusion $=$ $0)$. Thus, the rate constant of decline of caffeine-evoked $\mathrm{Ca}^{2+}$ transient $\left(r_{\text {caff }}\right)$ approximately reflects the rate of $\mathrm{Ca}^{2+}$ transport by NCX $\left(r_{\text {caff }}=r_{\mathrm{NCX}}\right)$. The rate constant of $\mathrm{Ca}^{2+}$ transport by SERCA2a was estimated by subtracting $r_{\text {caff }}$ from $r\left(r_{\text {SERCA }}=r-r_{\text {caff }}\right)$, while $r_{\text {caff }}$ was taken as an index of the rate of $\mathrm{Ca}^{2+}$ transport by NCX.

\section{Western Blotting}

For Western blotting, $\mathrm{H} 9 \mathrm{c} 2$ cells were treated with 10 $\mathrm{nmol} / \mathrm{L}$ bortezomib for time indicated. Rat heart mitochondria for this procedure were isolated as described above. The samples were washed with PBS and lysed with radioimmunoprecipitation assay buffer containing 50 $\mathrm{mmol} / \mathrm{L}$ Tris base, $150 \mathrm{mmol} / \mathrm{L} \mathrm{NaCl}, 1 \% \mathrm{NP}-40,0.25 \%$ sodium deoxycholate, and $1 \mathrm{mmol} / \mathrm{L}$ EDTA supplemented with Complete protease inhibitor cocktail tablets (Roche Diagnostics). Protein concentration was measured using Bio-Rad Protein Assay. Equal amounts of protein were separated on $12 \%$ SDS polyacrylamide gel, transferred onto Protran nitrocellulose membranes (Schleicher and Schuell BioScience Inc., Keene, NH), blocked with Tris-buffered saline (pH 7.4) and $0.05 \%$ Tween 20 , supplemented with $5 \%$ nonfat milk and $5 \%$ fetal bovine serum. The following antibodies at 1:1000 dilution were used for 24 -hour incubation at $4^{\circ} \mathrm{C}$ : mouse monoclonal anti-porin, mouse monoclonal anti-complex $\mathrm{V}$ $\alpha$ subunit, mouse monoclonal anti-complex $\vee \beta$ subunit, mouse monoclonal anti-complex $\mathrm{V}$ IF1 subunit, mouse monoclonal anti-complex I NDUFA9 subunit, mouse monoclonal anti-PDH E1 $\alpha$ subunit, and MitoProfile Total OXOPHOS Antibody Cocktail (all from Mitosciences Inc., Eugene, OR); mouse monoclonal anti $\alpha$-tubulin; rabbit anti- $\beta$-actin antiserum and rabbit polyclonal anti-LC3B (Sigma); mouse monoclonal anti-KDEL/BiP (Stressgen). After washing with Tris-buffered saline $(\mathrm{pH} 7.4)$ and $0.05 \%$ Tween 20 , membranes were incubated for 45 minutes with corresponding alkaline phosphatase-cou- 
A H9c2 cardiomyoblasts
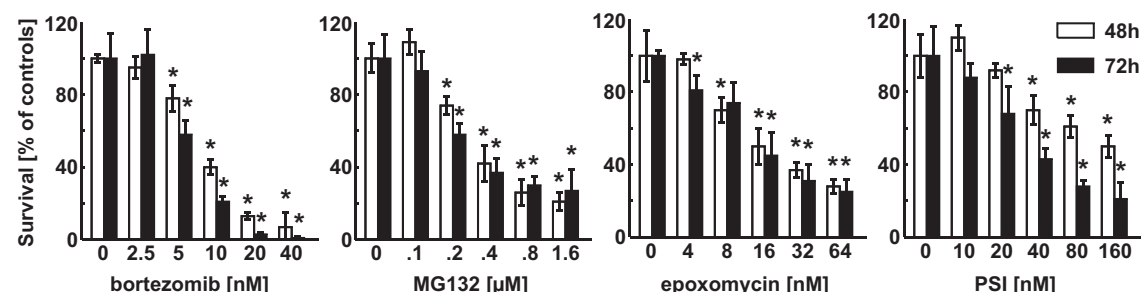

PSI [nM]
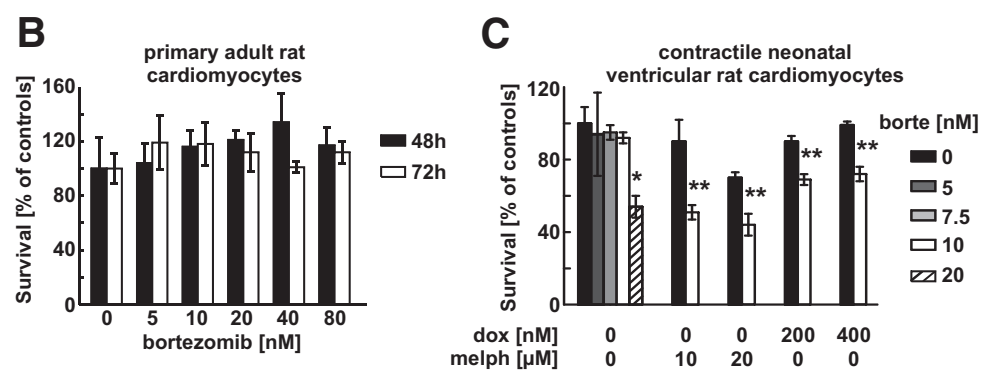

Figure 1. Proteasome inhibitors induce cytostat$\mathrm{ic} /$ cytotoxic effects in $\mathrm{H} 9 \mathrm{c} 2$ rat cardiac myoblast cells. A: $\mathrm{H} 9 \mathrm{c} 2$ cells were incubated for 48 or 72 hours with indicated concentrations of selected proteasome inhibitors: bortezomib, MG132, epoxomycin, and carbobenzoxyl-lle-Glu-(O-t-butyl)Ala-Leucinal (PSI). The cytostatic/cytotoxic effects were measured with crystal violet staining. B: Primary ventricular cardiomyocytes isolated from adult rats were incubated with bortezomib. The cytostatic/cytotoxic effects were measured with crystal violet staining. C: Contractile neonatal ventricular rat cardiomyocytes were incubated with bortezomib. The cytostatic/cytotoxic effects were measured with XTT assay. Bars represent percent survival versus untreated controls. Data are mean $\pm \mathrm{SD}{ }^{*} P<0.05$ versus controls (two-tailed Student's $t$-test). ${ }^{* *} P<0.05$ versus chemotherapy alone (two-tailed Student's $t$-test). pled secondary antibodies (Pierce). The reaction was developed using 1-Step nitro blue tetrazolium (NBT)/5bromo-4-chloro-3-indolyl phosphate Reagent (Pierce). After scanning, densitometric analysis of Western blots was performed using the Image Quant 5.2 software (Amersham Bioscience, Piscataway, NJ).

\section{Statistical Analysis}

Data were analyzed using Microsoft Excel 2007. Differences in cytostatic/cytotoxic effects, band densities, $\mathrm{Ca}^{2+}$ transient, and cell shortening, as well as in parameters measured in echocardiography were analyzed for significance by Student's t-test. Significance was defined as two-sided $P<0.05$.

\section{Results}

\section{Proteasome Inhibitors Are Toxic to H9c2 Rat Cardiomyoblastic Cells}

Bortezomib and three other proteasome inhibitors (MG132, carbobenzoxyl-Ile-Glu-(O-t-butyl)-Ala-Leucinal (PSI) and epoxomycin) reduced survival of $\mathrm{H} 9 \mathrm{c} 2$ rat cardiomyoblastic cells (Figure 1A). These effects were timeand dose-dependent and were observed at 5 to 10 $\mathrm{nmol} / \mathrm{L}$ concentrations, which are within the range inducing cytostatic/cytotoxic effects in human tumor cells (see Supplemental Figure S1A at http://ajp.amjpathol.org) and are found in the plasma of bortezomib-treated patients. ${ }^{16}$ Although bortezomib did not affect survival of primary adult rat ventricular cardiomyocytes (Figure 1B), it was cytotoxic to contractile neonatal ventricular rat cardiomyocytes at $20 \mathrm{nmol} / \mathrm{L}$ concentration (Figure 1C). Moreover, bortezomib at $10 \mathrm{nmol} / \mathrm{L}$ concentration potentiated cytotoxic effects of melphalan and doxorubicin against neonatal rat cardiomyocytes (Figure 1C). Dasatinib, imatinib, sorafenib, and sunitinib, other approved anticancer agents that were recently shown to induce cardiotoxic effects also induced cytostatic/cytotoxic effects in H9c2 cells, but at concentrations 2 to 3 orders of magnitude higher than bortezomib (see Supplemental Figure S1B at http://ajp.amjpathol.org). The imatinib-associated cardiotoxicity was proposed to result from induction of endoplasmic reticulum (ER) stress. ${ }^{2}$ Proteasome inhibition is also associated with induction of ER stress, ${ }^{17}$ which results from inhibition of protein retrotranslocation from the ER leading to accumulation of undegraded proteins. Bortezomib induced marked accumulation of polyubiquitinated proteins in $\mathrm{H} 9 \mathrm{c} 2$ cells (Figure 2A), accompanied by induction of ER stress with induction of binding protein (BiP) expression (Figure $2 \mathrm{~B}$ ) and pronounced widening of ER lumen observed under TEM (Figure 2C). Impaired proteasomal removal of damaged or misfolded proteins was reported to induce formation of large protein aggregates and compensatory induction of autophagy in primary rat cardiomyocytes. ${ }^{18}$ Incubation of $\mathrm{H} 9 \mathrm{c} 2$ cardiomyoblasts with bortezomib led to the formation of multilamellar and lysosomal/autophagosomal structures observed under TEM (Figure 2C). Aggregation of GFPtagged LC3 (Figure 2D) and increased LC3 processing (Figure 2E) in $\mathrm{H} 9 \mathrm{c} 2$ cells further confirmed that bortezomib induces autophagy in cardiomyoblasts.

\section{Bortezomib Reversibly Impairs Systolic Heart Muscle Function in Rats}

Although $\mathrm{H} 9 \mathrm{c} 2$ cells are frequently used to examine cardiac-related effects of drugs, ${ }^{19}$ there are limitations to in vitro studies with these cells, which unlike normal cardiomyocytes are dividing and do not present all features of mature cardiomyocytes, such as contractility. Nonetheless, significant toxicity and the induction of ER stress and autophagy observed in response to accumulation of 
A
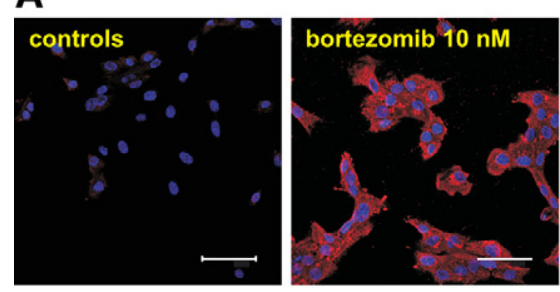

C

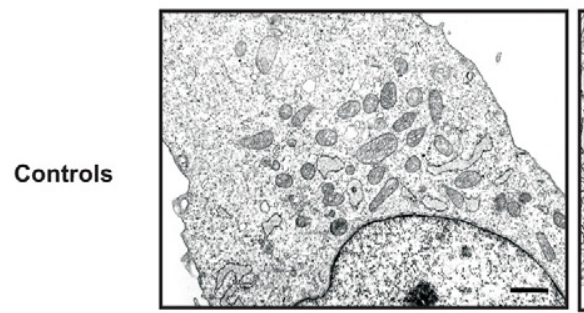

B
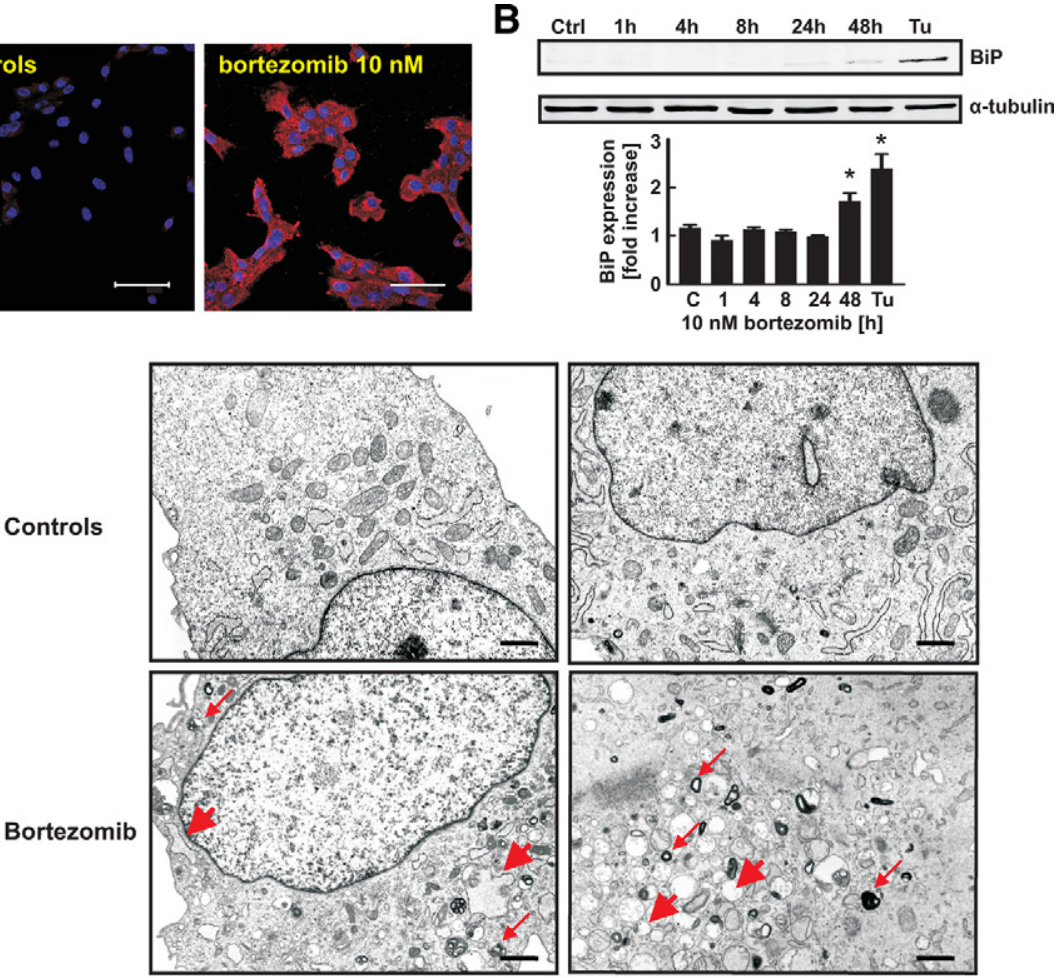

D
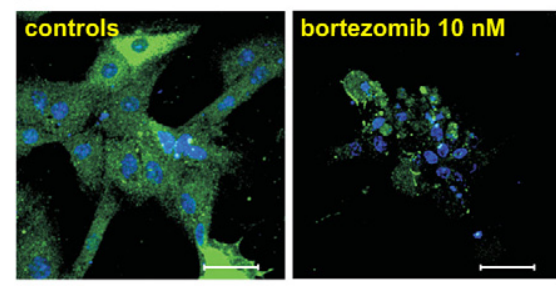

E
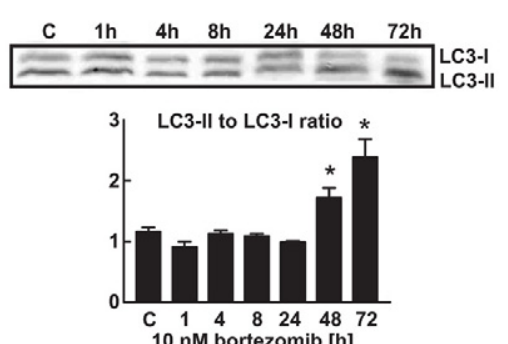

Figure 2. Bortezomib induces ER stress and autophagy in $\mathrm{H} 9 \mathrm{c} 2$ cells.A: H9c2 cells were in cubated for 24 hours with $10 \mathrm{nmol} / \mathrm{L}$ bortezomib and subjected to indirect immunofluorescence microscopy using anti-FK2 (multiubiquitin) antibody (red) and 4,6-diamidino-2-phenylindole staining (blue). Scale bars $=75 \mu \mathrm{m}$. B: $\mathrm{H} 9 \mathrm{c} 2$ cells were incubated with $10 \mathrm{nmol} / \mathrm{L}$ bortezomib for indicated periods. Total cell lysates were prepared and Western blot analysis was performed using anti-BiP and anti- $\alpha$ tubulin antibodies. Cells incubated for 16 hours with $10 \mu \mathrm{g} / \mathrm{ml}$ tunicamycin were used as a positive control. Data are mean $\pm \mathrm{SE}{ }^{*} P<0.05$ versus controls (twotailed Student's $t$-test). C: $\mathrm{H} 9 \mathrm{c} 2$ cells were incubated for 48 hours with $10 \mathrm{nmol} / \mathrm{L}$ bortezomib, collected, and fixed as described in Materials and Methods, and observed by TEM. Thin red arrows indicate multilamellar and/or lysosomal/autophagosomal structures; thick red arrows point to widened endoplasmic reticulum. Scale bars $=200 \mathrm{~nm}$. D: H9c2 cells were transiently transfected with pEGFP-LC3m plasmid encoding EGFP-LC3 fusion protein, incubated for 48 hours with $10 \mathrm{nmol} / \mathrm{L}$ bortezomib, fixed, stained with anti-GFP antibody and TO-PRO nuclear stain and observed under fluorescence microscopy. Scale bars $=75 \mu \mathrm{m}$. E: H9c2 cells were incubated with $10 \mathrm{nmol} / \mathrm{L}$ bortezomib for the indicated periods. Then total cell lysates were prepared and Western blot analysis was performed using anti-LC3B antibody against LC3B-I and LC3B-II fragments (upper panel) Densitometric analysis of LC3B-II to LC3B-I ratio in $\mathrm{H} 9 \mathrm{c} 2$ cells (lower panel). Data are mean \pm SE ${ }^{*} P<0.05$ versus controls (two-tailed Student's $t$-test). polyubiquitinated proteins in normal cardiomyocytes prompted us to evaluate the influence of bortezomib on cardiac function in animals. Wistar rats were treated thrice weekly with $0.2 \mathrm{mg} / \mathrm{kg}$ of bortezomib for 3 weeks. This dose was shown previously to produce blood concentrations of bortezomib comparable with those seen in humans. ${ }^{20}$ Echocardiographic analysis revealed left ventricular contractile dysfunction manifested by a significant drop in left ventricle ejection fraction which was detected already after second dose of bortezomib (Figure 3A). This effect was accompanied by proportional decrease in LV fractional shortening (Figure 3B) and a rise in LV systolic area (Figure $3 C$ ). There were no changes in LV diastolic area (Figure 3D), heart rate, or blood pressure in bortezomib-treated rats.

\section{Bortezomib Treatment Leads to Sporadic Cardiomyocyte Hypertrophy Associated with Profound Mitochondrial Abnormalities}

H\&E staining of heart sections obtained from bortezomibtreated rats revealed that although the myocardium as a whole was not hypertrophic, there were scattered regions containing enlarged cardiomyocytes (Figure 4, A and B) accompanied by capillary tunneling (invagination of capillaries within cardiomyocytes, Figure 4, E and F), and cardiomyocyte vacuolization (Figure 4, C and D). Mean cardiomyocyte diameter (Figure 4G) and posterior left ventricle wall thickness (Figure $4 \mathrm{H}$ ) did not vary between controls and bortezomib-treated groups, and Picrosirius staining did not reveal any increase in the collagen-rich areas in the hearts from bortezomib-treated rats (Figure 4I). Ultrastructural analysis of randomly sampled cardiac muscle obtained from bortezomib-treated rats revealed multiple abnormalities, with the most prominent changes observed within mitochondria, which were pleomorphic, enlarged, contained concentric cristae, and numerous inclusions (including glycogen-like granules) that grouped into large intermyofibrillar clusters (Figure 5A, and Supplemental Figure S2 at http://ajp.amjpathol.org). The myofibrillar lattice was heavily disordered at 1 week of bortezomib treatment and completely disarrayed 2 weeks later. All these abnormalities were most frequent at subsarcoplasmic regions, especially in perivascular cardiomyocytes. Degenerations within adhering junctions of intercalated disks with annular nexuses invaginating into 
A

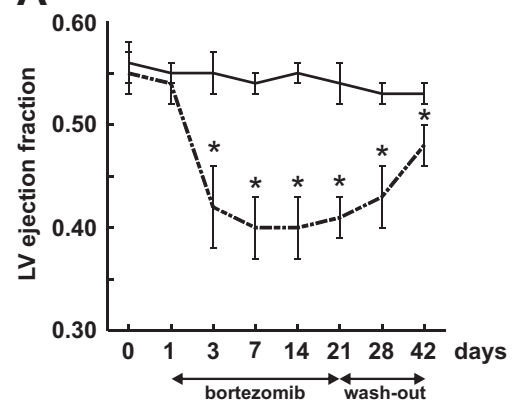

C

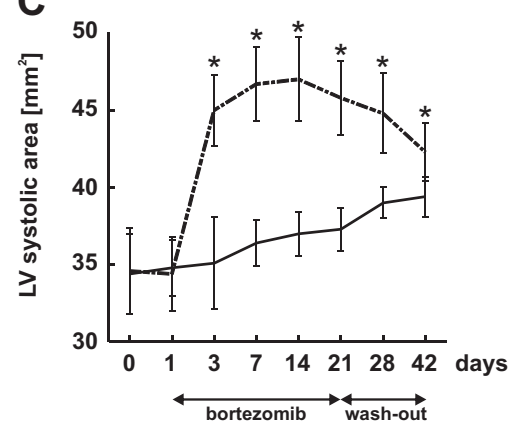

B
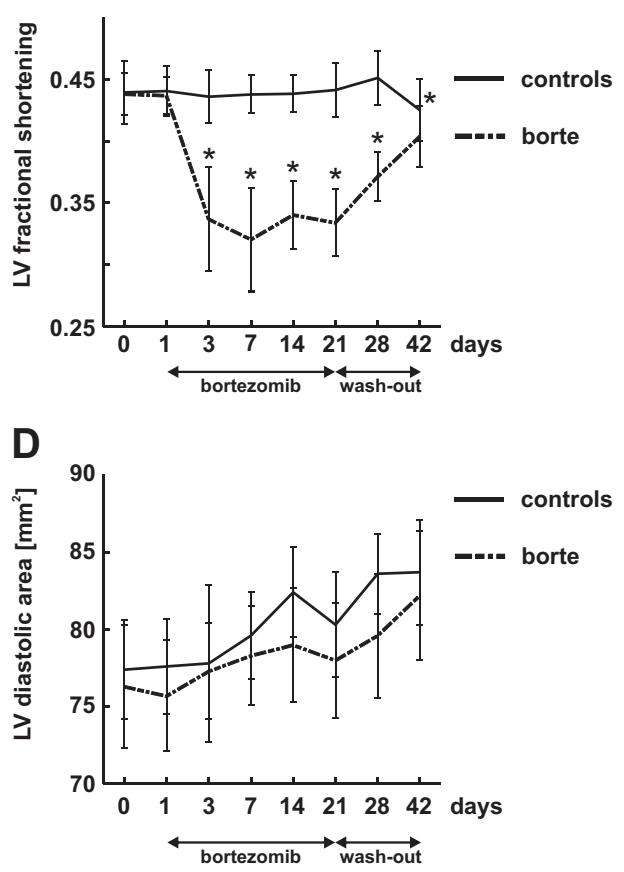

Figure 3. Bortezomib reversibly impairs systolic, but not diastolic, heart muscle function in rats Wistar rats were treated for 3 weeks with 0.2 $\mathrm{mg} / \mathrm{kg}$ i.p. bortezomib (thrice weekly) followed by 3-week wash-out. Control animals received diluent. At indicated time points, echocardiographic examination was performed. Graphs present selected echocardiographic parameters in bortezomib-treated rats (scattered line) and control animals (solid line). Data are mean $\pm \mathrm{SD}$. ${ }^{*} P<0.001$ vs controls (two-tailed Student's $t$-test). A: LV ejection fraction. B: LV fractional shortening. C: LV systolic area. D: LV diastolic area. cardiac myocytes were also observed. Other abnormalities found in bortezomib-treated hearts included scattered lipid droplets, numerous vacuoles, and lysosomal/ autophagosomal structures. Similar changes were also observed in hearts of bortezomib-treated mice (see Supplemental Figure S3 at http://ajp.amjpathol.org).

\section{Bortezomib Impairs Mitochondrial Function in} Rat Hearts

Considering the profound mitochondrial abnormalities observed in hearts of bortezomib-treated rats, we decided to determine the respiratory activity of cardiac
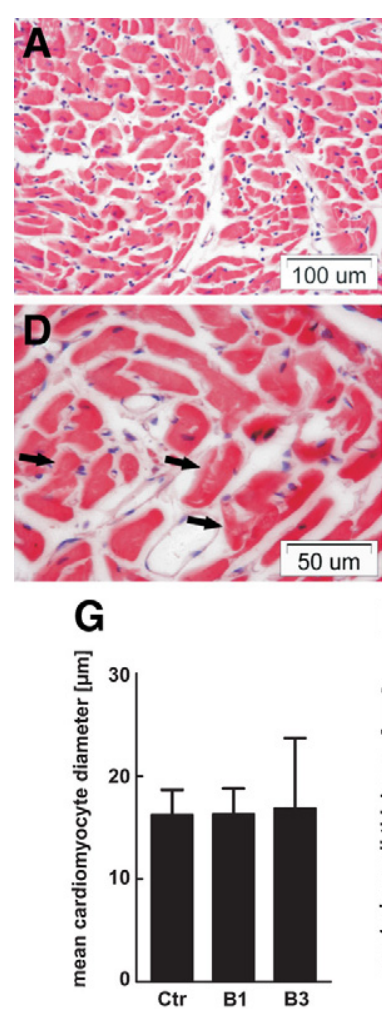

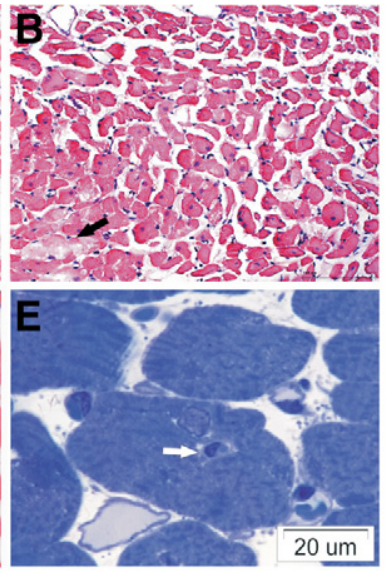

H

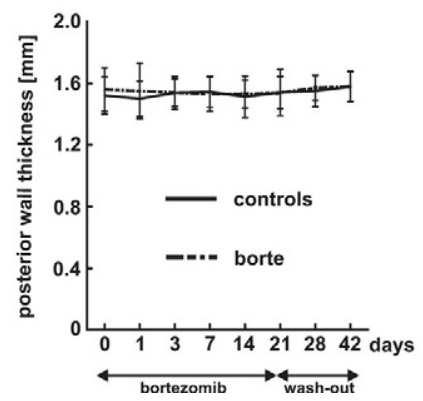

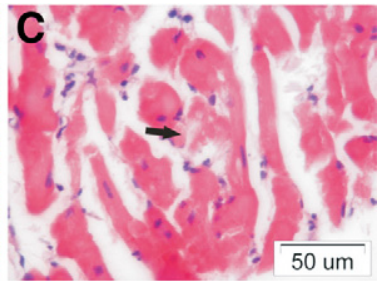

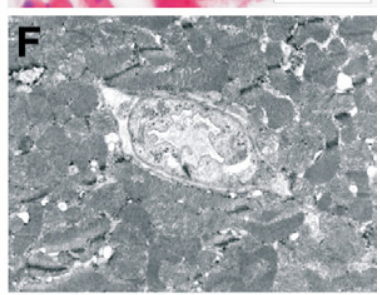

I

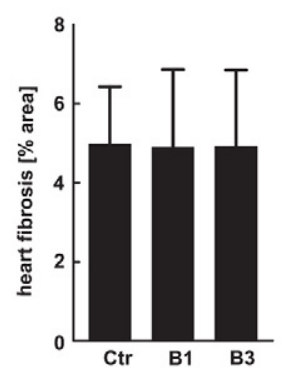

Figure 4. Morphological changes in hearts of bortezomib-treated rats. Male Wistar rats were treated for one or three weeks with $0.2 \mathrm{mg} / \mathrm{kg}$ i.p. bortezomib (thrice weekly). Control animals received diluent. Figure presents cross section fragments of left ventricles. A-D: H\&E staining showing (A) control animals; (B) rats treated with bortezomib for three weeks-a group of hypertrophied cardiomyocytes in the lower left corner; among them damaged cardiac myocytes as seen by diminished eosinophilia of the cytoplasm, marked by the black arrow; $(\mathbf{C , D})$ rats treated with bortezomib for three weeks-vacuolized cardiac myocytes marked with black arrows. E: Rats treated with bortezomib for three weeks-semithin section stained with toluidine blue depicting a tunnel capillary (marked with the white arrow). F: Rats treated with bortezomib for three weeks-TEM photograph of a tunnel capillary within cardiac myocyte. G Mean diameter of cardiomyocytes in rat hearts: control (ctr), bortezomib-treated for one week (B1), and bortezomib-treated for three weeks (B3). H: Echocardiographic measurements of the left ventricle posterior wall thickness. I: Quantitative data from Picrosirius red-stained tissue sections to mark collagen-rich areas. 
A

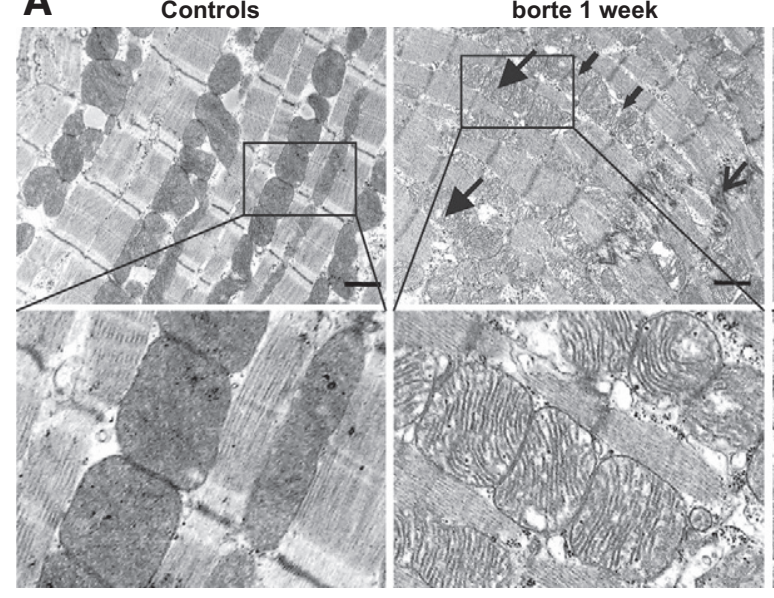

B

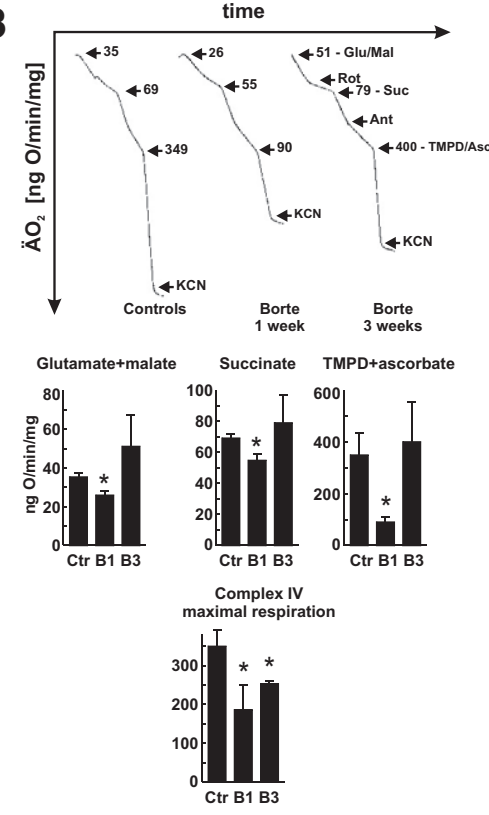

C

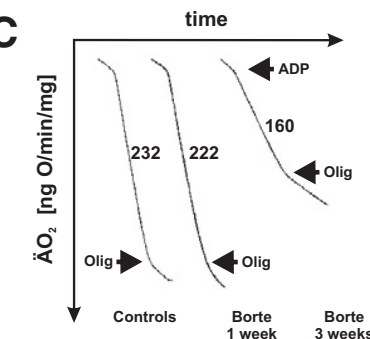

State III (ATP synthesis)

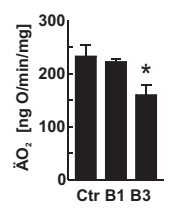

D

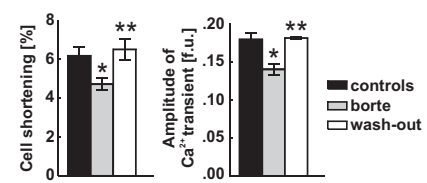

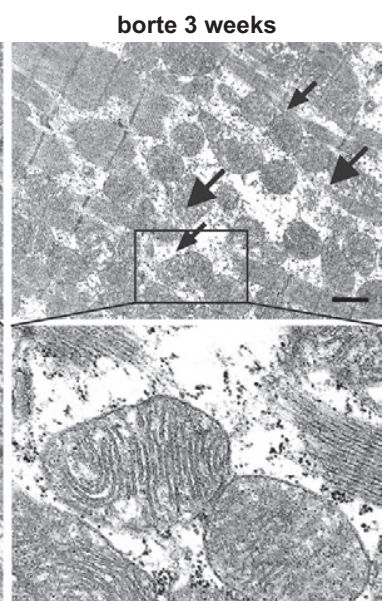

Figure 5. Bortezomib-induced mitochondrial changes in rats. A: Transmission electron microscopy of heart left ventricles. Wistar rats were treated for 1 or 3 weeks with $0.2 \mathrm{mg} / \mathrm{kg}$ i.p. bortezomib (thrice weekly). Control animals received diluent. At indicated time points hearts were perfused with fixative and subjected to TEM. Large arrowheads indicate enlarged and disrupted mitochondria, small arrowhead shows disorganized myofilaments, small arrows depict mitochondrial inclusions, while large arrow points at degeneration of adhering junction. Insets show enlarged views of the marked areas. Scale bars $=1 \mu \mathrm{m}$. B: Oxygen consumption of mitochondria isolated form hearts of control and bortezomib-treated rats. Upper panel shows representative linear plots of oxygen consumption; numbers refer to mean oxygen consumption values for indicated respiratory states. Lower panel presents calculated mean oxygen consumption $\pm \mathrm{SD}$ in control rats (Ctr), and rats treated with bortezomib for one week (B1) or three weeks (B3). Glutamate/ malate, succinate, and tetramethylphenylenediamine (TMPD)/ascorbate graphs represent respiration with indicated substrates, respectively. Lower graph shows respiration rate of submitochondrial particles obtained by freeze-thawing disruption of mitochondria integrity. Data are mean $\pm \mathrm{SD} .{ }^{*} P<0.05$ versus controls (twotailed Student's $t$-test). C: Oxygen consumption after ADP addition to heart mitochondria. Upper panel shows representative linear plots of oxygen consumption; numbers refer to mean oxygen consumption values after ADP addition. Lower panel presents mean oxygen consumption $\pm \mathrm{SD}$ in control rats (Ctr), and rats treated with bortezomib for one week (B1) or three weeks (B3). Data are mean $\pm \mathrm{SD} .{ }^{*} P<0.05$ versus controls (two-tailed Student's $t$-test). D: Bortezomib reversibly impairs cell shortening (left panel) and amplitude of calcium ion transient (right panel) in cardiomyocytes isolated from left ventricle of bortezomib-treated and control rats. Data are mean $\pm \mathrm{SD} .{ }^{*} P<0.05$ versus controls, ${ }^{* *} P<0.05$ versus bortezomibtreated group (two-tailed Student's $t$-test). mitochondria isolated from bortezomib-treated rats. Suppressed oxygen consumption under resting state conditions (measured with glutamate + malate, succinate, or tetramethylphenylenediamine (TMPD) + ascorbate, as respiratory substrates for complexes I, II, and IV, respectively) was observed within 1 week of bortezomib treatment (Figure 5B). However, 2 weeks later, mitochondrial oxygen consumption returned to control values. Moreover, we measured respiration rate of submitochondrial particles (obtained by freezing-thawing of mitochondria) with an artificial electron donor for cytochrome $c$ oxidase (complex IV) and in the presence of exogenous cytochrome $c$. At this condition, the maximal respiration rate was limited only by the respiratory efficiency of complex IV. Respiration was suppressed by $47 \%$ and $28 \%$, after 1 and 3 weeks of bortezomib treatment, respectively (Figure $5 \mathrm{~B}$ ). These results indicate that bortezomib treatment is associated with inhibition of complex IV of the mitochondrial respiratory chain. Moreover, after 3 weeks of bortezomib treatment mitochondrial ATP production (measured as the increase of mitochondrial respiration after ADP addition-state III) was decreased by $31 \%$, while 1-week treatment was without effect (Figure 5C). Western blotting analysis of heart mitochondrial fractions revealed decreased expression of complex $V$ subunits in rats treated with bortezomib for 3 weeks, and no changes in the expression of other components of the respiratory chain (see Supplemental Figure S4 at http://ajp.amjpathol.org). The decreased ATP synthesis observed at 3 weeks of bortezomib treatment was accompanied by a $24 \%$ decrease in cardiomyocyte shortening, as well as a $22 \%$ decrease in the amplitude of $\mathrm{Ca}^{2+}$ transients (Figure 5D). These changes were reversible within 2 weeks of bortezomib wash-out as the amplitudes of both signals returned to control values (Figure 5D). Bortezomib treatment did not affect the rate of $\mathrm{Ca}^{2+}$ transient decay (rate of $\mathrm{Ca}^{2+}$ removal from the cytosol) (see Supplemental Figure S5 at http://ajp.amjpathol.org) or diastolic $\mathrm{Ca}^{2+}$ concentration (not shown). The rate of $\mathrm{Ca}^{2+}$ transport by sarcoplasmic reticulum $\mathrm{Ca}^{2+}$-ATP-ase (SERCA2a) and $\mathrm{Na}^{+} / \mathrm{Ca}^{2+}$ exchanger (NCX) and thus their contribution to relaxation did not change in myocytes from bort- 
ezomib-treated rats (see Supplemental Figure S5 at http://ajp.amjpathol.org).

\section{Discussion}

The studies presented here show that bortezomib treatment impairs cardiac function. The mechanism(s) of these effects remain to be elucidated, but do not seem to result from induction of cardiomyocyte death, as no necrotic or apoptotic cells/areas were found in histopathological heart examination by terminal deoxynucleotidyl transferase-mediated dUTP nick-end labeling or TEM. These observations are in agreement with previous finding indicating that proteasome inhibitors induce apoptosis in proliferating rather than quiescent cells. ${ }^{21}$ Moreover, there was no rise in plasma troponin I levels (not shown) or increased heart fibrosis (Figure 4I) in bortezomib-treated animals and no cytostatic/cytotoxic effects of bortezomib were observed in primary cultures of adult rat cardiomyocytes (Figure 1B). Cytotoxic effects of bortezomib were observed in proliferating $\mathrm{H} 9 \mathrm{c} 2$ cardiomyoblasts or in contractile, ie, metabolically active neonatal ventricular rat cardiomyocytes, although only at relatively high $20 \mathrm{nmol} / \mathrm{L}$ concentrations in the latter (Figure 1C). Although bortezomib used at $10 \mathrm{nmol} / \mathrm{L}$ concentration did not affect viability of neonatal cardiomyocytes when used alone, it significantly potentiated cytotoxic effects of melphalan, which is usually used together with bortezomib in multiple myeloma patients, ${ }^{22}$ or doxorubicin, which is cardiotoxic and used together with bortezomib in clinical trials. ${ }^{23}$ Bortezomib-induced cardiac effects seem to be reversible, as demonstrated during wash-out experiments (Figure 3). These observations confirm that bortezomib is not inducing irreversible damage to cardiomyocytes, which is consistent with lack of apoptosis in gross histopathological examination on terminal deoxynucleotidyl transferase-mediated dUTP nick-end labeling. Rather, it seems that bortezomib impairs cardiomyocyte function through disruption of mitochondrial energetics. A $31 \%$ drop in ATP concentration is comparable with a 35\% decline in ATP induced by herceptin, ${ }^{24}$ a monoclonal antibody that exerts cardiotoxic effects. It can be expected that this drop should not compromise cellular processes in many types of cells. However, cardiomyocytes are contractile cells with an extremely high demand for ATP. Therefore, they might be particularly sensitive to agents that perturb mitochondrial activity. The mechanism(s) of bortezomib-induced mitochondrial defects remain to be elucidated. Many other drugs that exert cardiotoxic effects also induce profound mitochondrial abnormalities. 2,19,24,25 Interestingly, it was recently reported that multiple proteins of the outer mitochondrial membrane are degraded by proteasomes following ubiquitination and extraction from the membrane in a manner similar to ER-associated degradation. ${ }^{26}$ Cardiomyocytes might turn out to be especially susceptible to inhibition of mitochondrial protein retrotranslocation due to their incessant contractile activity that requires continuous respiratory chain engagement. It has been estimated that approximately 1 to $2 \%$ of total oxygen consumed during aerobic metabolism is converted into reactive oxygen species, primarily $\mathrm{O}_{2}{ }^{\bullet-} .27$ Reactive oxygen species might be involved in damage to mitochondrial proteins that would require proteasomal degradation to avoid their cross-linking, unfolding, or aggregation. It will require further studies to see whether proteasome inhibition is associated with impaired retrotranslocation of mitochondrial proteins in cardiomyoblasts.

Histopathology examinations of heart sections from bortezomib-treated rats revealed induction of capillary tunneling. Tunnel capillaries, capillaries which run through the cardiac cells, have been described for the first time in hypertrophied hearts of spontaneously hypertensive rats. ${ }^{28}$ Their occurrence within cardiac cells seems to be related to cardiomyocyte hypertrophy or increased metabolic demand. Relative hypoxia might also be the signal for the growth of capillary into a cardiac cell and might be the result of angiogenesis, ie, the sprouting of microvessel from the adjacent intercellular capillary. Another possibility is that a segment of pre-existing intercellular capillary invaginates into a cardiomyocyte during remodeling of the myocardium. This second possibility is described as the remodeling theory. ${ }^{29}$ In both cases, the tunnel capillaries are present only within the hypertrophied cardiomyocytes. In our experiments we observed only sporadic scattered areas of cardiomyocyte hypertrophy (which means that only some of them were hypertrophied) in bortezomib-treated rats. Since proteasome inhibitors exert anti-angiogenic activity, we presume that the trigger for capillary tunneling is an increased metabolic demand resulting from decreased ATP synthesis, rather than induction of angiogenesis. We do not know what the pathological significance of capillary tunneling in bortezomib-treated rats is, or whether tunneling may improve oxygenation of cardiac tissue, but it is highly probable that this phenomenon is an adaptive response to cardiomyocyte hypertrophy and/or increased metabolic demand resulting from decreased ATP synthesis.

Bortezomib used in this study was administered at a dose of $0.2 \mathrm{mg} / \mathrm{kg}$ thrice weekly in rats and at a dose of $1 \mathrm{mg} / \mathrm{kg}$ every second day in mice. This dosing schedule is slightly more intensive than in humans, where bortezomib is used every 72 hours at a dose of $1.3 \mathrm{mg} / \mathrm{m}^{2}$. However, rodents usually require higher drug administration schedules than humans and we have used bortezomib doses that are most frequently used in rodent experiments. ${ }^{30,31}$ Moreover, $0.2 \mathrm{mg} / \mathrm{kg}$ dose was shown to produce bortezomib blood concentrations comparable with those seen in humans. ${ }^{20} \mathrm{~A}$ multinational pharmaceutical company survey performed by Olson et al ${ }^{32}$ revealed that $94 \%$ of toxicities observed in at least two animal species predicted human toxicities in clinical trials. The observation of similar mitochondrial changes in rats and mice highly underscores the clinical relevance of preclinical bortezomib-associated effects revealed in this study.

There are ambiguous reports on the influence of proteasome inhibitors on cardiac function. Proteasome inhibitors have been reported to suppress cardiomyocyte hypertrophy, ${ }^{33}$ decrease cardiac remodeling in a mouse pressure-overload model, and prevent cardiomyocyte 
damage induced by hyperthermic or oxidative injury. ${ }^{34}$ However, in many of those studies, proteasome inhibitors were used either transiently at suboptimal doses or preceded a heart-stressing procedure. Therefore, proteasome inhibitors might induce a hormeotic effect, preconditioning cardiac tissue to ensuing stress or damage. On the other hand, accumulation of polyubiquitinated proteins has been reported in human heart failure suggesting impaired ubiquitin-proteasome system function. ${ }^{35,36}$ In animal studies, aortic banding that leads to heart failure is associated with decreased proteasome activities, accumulation of ubiquitinated proteins ${ }^{37}$ and ER stress. ${ }^{38}$ Depressed proteasome function in pressure-overloaded hearts preceded development of heart failure. ${ }^{37}$ Moreover, a recent study in mice reported that pressure overload promotes accumulation of ubiquitinated protein aggregates in the left ventricle. ${ }^{18}$ Impaired ubiquitinproteasome system activity has also been proposed to contribute to pathological changes that develop after myocardial ischemia. ${ }^{39}$ Pretreatment of isolated hearts with lactacystin led to accumulation of oxidized proteins in postischemic heart. ${ }^{40} \mathrm{~A}$ recent study has also demonstrated that proteasome inhibitors (MG132 and epoxomycin) induce ER stress-initiated death of $\mathrm{H} 9 \mathrm{c} 2$ cells. ${ }^{41}$ All these observations indicate that systemic proteasome inhibition might not be as safe as was initially observed. However, caution must be exercised in translating these findings into clinic as the occurrence and extent of bortezomib-induced cardiotoxicity in cancer patients are currently unknown, and patients treated with bortezomib need careful monitoring for cardiac function. In a recent phase III clinical study of bortezomib used in combination with pegylated liposomal doxorubicin, LV ejection fraction was reported to decrease in $7 \%$ of patients treated with bortezomib. ${ }^{23}$ In another clinical study, grade 3 to 4 cardiac heart failure was reported in 2 cases (one fatal) receiving bortezomib in combination with doxorubicin or with doxorubicin and dexamethasone. ${ }^{42}$ Patients with pre-existing cardiovascular diseases or treated with other cardiotoxic regimens (including anthracyclines) may be at particular risk of cardiac failure, and will need a closer follow-up. Prospective studies that will evaluate cardiac effects of bortezomib are needed.

\section{Acknowledgments}

We thank Elzbieta Gutowska and Anna Czerepinska for excellent technical assistance.

\section{References}

1. Slamon DJ, Leyland-Jones B, Shak S, Fuchs H, Paton V, Bajamonde A, Fleming T, Eiermann W, Wolter J, Pegram M, Baselga J, Norton L: Use of chemotherapy plus a monoclonal antibody against HER2 for metastatic breast cancer that overexpresses HER2. N Engl J Med 2001, 344:783-792

2. Kerkela R, Grazette L, Yacobi R, lliescu C, Patten R, Beahm C, Walters B, Shevtsov S, Pesant S, Clubb FJ, Rosenzweig A, Salomon RN, Van Etten RA, Alroy J, Durand JB, Force T: Cardiotoxicity of the cancer therapeutic agent imatinib mesylate. Nat Med 2006, 12:908-916
3. Mego M, Reckova M, Obertova J, Sycova-Mila Z, Brozmanova K Mardiak J: Increased cardiotoxicity of sorafenib in sunitinib-pretreated patients with metastatic renal cell carcinoma. Ann Oncol 2007, 18:1906-1907

4. Schmidinger M, Zielinski CC, Vogl UM, Bojic A, Bojic M, Schukro C, Ruhsam M, Hejna M, Schmidinger H: Cardiac toxicity of sunitinib and sorafenib in patients with metastatic renal cell carcinoma. J Clin Oncol 2008, 26:5204-5212

5. Aghajanian C, Soignet S, Dizon DS, Pien CS, Adams J, Elliott PJ, Sabbatini P, Miller V, Hensley ML, Pezzulli S, Canales C, Daud A, Spriggs DR: A phase I trial of the novel proteasome inhibitor PS341 in advanced solid tumor malignancies. Clin Cancer Res 2002, 8:2505-2511

6. Argyriou AA, Iconomou G, Kalofonos HP: Bortezomib-induced peripheral neuropathy in multiple myeloma: a comprehensive review of the literature. Blood 2008, 112:1593-1599

7. Voortman J, Giaccone G: Severe reversible cardiac failure after bortezomib treatment combined with chemotherapy in a non-small cell lung cancer patient: a case report. BMC Cancer 2006, 6:129

8. Orciuolo E, Buda G, Cecconi N, Galimberti S, Versari D, Cervetti G, Salvetti A, Petrini M: Unexpected cardiotoxicity in haematological bortezomib-treated patients. Br J Haematol 2007, 138:396-397

9. Hacihanefioglu A, Tarkun P, Gonullu E: Acute severe cardiac failure in a myeloma patient due to proteasome inhibitor bortezomib. Int $\mathrm{J} \mathrm{He}$ matol 2008, 88:219-222

10. Kabeya Y, Mizushima N, Ueno T, Yamamoto A, Kirisako T, Noda T, Kominami E, Ohsumi Y, Yoshimori T: LC3, a mammalian homologue of yeast Apg8p, is localized in autophagosome membranes after processing. EMBO J 2000, 19:5720-5728

11. Schaller H, Letko G, Kunz W: Influence of Mg2+-ions on the properties of rat heart mitochondria in dependence on the preparation. Acta Biol Med Ger 1978, 37:31-38

12. Nowis D, Legat M, Grzela T, Niderla J, Wilczek E, Wilczynski GM, Glodkowska E, Mrowka P, Issat T, Dulak J, Jozkowicz A, Was H, Adamek M, Wrzosek A, Nazarewski S, Makowski M, Stoklosa T, Jakobisiak M, Golab J: Heme oxygenase-1 protects tumor cells against photodynamic therapy-mediated cytotoxicity. Oncogene 2006, 25:3365-3374

13. Mackiewicz U, Emanuel K, Lewartowski B: Voltage dependent activation of tonic contraction in cardiac myocytes. J Physiol Pharmacol 2003, 54:409-421

14. Spurgeon HA, Stern MD, Baartz G, Raffaeli S, Hansford RG, Talo A, Lakatta EG, Capogrossi MC: Simultaneous measurement of $\mathrm{Ca} 2+$, contraction, and potential in cardiac myocytes. Am J Physiol 1990, 258:H574-586

15. Choi HS, Eisner DA: The role of sarcolemmal Ca2+-ATPase in the regulation of resting calcium concentration in rat ventricular myocytes. J Physiol 1999, 515 (Pt 1):109-118

16. Leveque D, Carvalho MC, Maloisel F: Review. Clinical pharmacokinetics of bortezomib. In Vivo 2007, 21:273-278

17. Fribley $A$, Zeng Q, Wang CY: Proteasome inhibitor PS-341 induces apoptosis through induction of endoplasmic reticulum stress-reactive oxygen species in head and neck squamous cell carcinoma cells. Mol Cell Biol 2004, 24:9695-9704

18. Tannous P, Zhu H, Nemchenko A, Berry JM, Johnstone JL, Shelton JM, Miller FJ, Jr., Rothermel BA, Hill JA: Intracellular protein aggregation is a proximal trigger of cardiomyocyte autophagy. Circulation 2008, 117:3070-3078

19. Will Y, Dykens JA, Nadanaciva S, Hirakawa B, Jamieson J, Marroquin LD, Hynes J, Patyna S, Jessen BA: Effect of the multitargeted tyrosine kinase inhibitors imatinib, dasatinib, sunitinib, and sorafenib on mitochondrial function in isolated rat heart mitochondria and H9c2 cells. Toxicol Sci 2008, 106:153-161

20. Hemeryck A, Geerts R, Monbaliu J, Hassler S, Verhaeghe T, Diels L, Verluyten W, van Beijsterveldt L, Mamidi RN, Janssen C, De Coster R: Tissue distribution and depletion kinetics of bortezomib and bortezomib-related radioactivity in male rats after single and repeated intravenous injection of $14 \mathrm{C}$-bortezomib. Cancer Chemother Pharmacol 2007, 60:777-787

21. Drexler HC, Risau W, Konerding MA: Inhibition of proteasome function induces programmed cell death in proliferating endothelial cells. FASEB J 2000, 14:65-77

22. Curran MP, McKeage K: Bortezomib: a review of its use in patients with multiple myeloma. Drugs 2009, 69:859-888 
23. Orlowski RZ, Nagler A, Sonneveld P, Blade J, Hajek R, Spencer A, San Miguel J, Robak T, Dmoszynska A, Horvath N, Spicka I, Sutherland HJ, Suvorov AN, Zhuang SH, Parekh T, Xiu L, Yuan Z, Rackoff W, Harousseau JL: Randomized phase III study of pegylated liposomal doxorubicin plus bortezomib compared with bortezomib alone in relapsed or refractory multiple myeloma: combination therapy improves time to progression. J Clin Oncol 2007, 25:3892-3901

24. Grazette LP, Boecker W, Matsui T, Semigran M, Force TL, Hajjar RJ, Rosenzweig A: Inhibition of ErbB2 causes mitochondrial dysfunction in cardiomyocytes: implications for herceptin-induced cardiomyopathy. J Am Coll Cardiol 2004, 44:2231-2238

25. Berthiaume JM, Wallace KB: Adriamycin-induced oxidative mitochondrial cardiotoxicity. Cell Biol Toxicol 2007, 23:15-25

26. Neutzner A, Youle RJ, Karbowski M: Outer mitochondrial membrane protein degradation by the proteasome. Novartis Found Symp 2007, 287:4-14; discussion 14-20

27. Giorgio M, Trinei M, Migliaccio E, Pelicci PG: Hydrogen peroxide: a metabolic by-product or a common mediator of ageing signals? Nature Rev Mol Cell Biol 2007, 8:722-728

28. Kawamura K, Kashii C, Imamura K: Ultrastructural changes in hypertrophied myocardium of spontaneously hypertensive rats. Jpn Circ J 1976, 40:1119-1145

29. Kobayashi M, Kawamura K, Honma M, Masuda H, Suzuki Y, Hasegawa $\mathrm{H}$ : Tunnel capillaries of cardiac myocyte in pressure-overloaded rat heart-an ultrastructural three-dimensional study. Microvasc Res 1999, $57: 258-272$

30. Henninger N, Sicard KM, Bouley J, Fisher M, Stagliano NE: The proteasome inhibitor VELCADE reduces infarction in rat models of focal cerebral ischemia. Neurosci Lett 2006, 398:300-305

31. Sunwoo JB, Chen Z, Dong G, Yeh N, Crowl Bancroft C, Sausville E, Adams J, Elliott P, Van Waes C: Novel proteasome inhibitor PS-341 inhibits activation of nuclear factor-kappa B, cell survival, tumor growth, and angiogenesis in squamous cell carcinoma. Clin Cancer Res 2001, 7:1419-1428

32. Olson H, Betton G, Robinson D, Thomas K, Monro A, Kolaja G, Lilly P, Sanders J, Sipes G, Bracken W, Dorato M, Van Deun K, Smith P, Berger B, Heller A: Concordance of the toxicity of pharmaceuticals in humans and in animals. Regul Toxicol Pharmacol 2000, 32:56-67

33. Meiners S, Dreger H, Fechner M, Bieler S, Rother W, Gunther C, Baumann G, Stangl V, Stangl K: Suppression of cardiomyocyte hypertrophy by inhibition of the ubiquitin-proteasome system. Hypertension 2008, 51:302-308
34. Luss H, Schmitz W, Neumann J: A proteasome inhibitor confers cardioprotection. Cardiovasc Res 2002, 54:140-151

35. Hein S, Arnon E, Kostin S, Schonburg M, Elsasser A, Polyakova V Bauer EP, Klovekorn WP, Schaper J: Progression from compensated hypertrophy to failure in the pressure-overloaded human heart: structural deterioration and compensatory mechanisms. Circulation 2003, 107:984-991

36. Birks EJ, Latif N, Enesa K, Folkvang T, Luong le A, Sarathchandra P, Khan M, Ovaa H, Terracciano CM, Barton PJ, Yacoub MH, Evans PC: Elevated p53 expression is associated with dysregulation of the ubiquitin-proteasome system in dilated cardiomyopathy. Cardiovasc Res 2008, 79:472-480

37. Tsukamoto O, Minamino T, Okada K, Shintani Y, Takashima S, Kato H, Liao Y, Okazaki H, Asai M, Hirata A, Fujita M, Asano Y, Yamazaki $\mathrm{S}$, Asanuma H, Hori M, Kitakaze M: Depression of proteasome activities during the progression of cardiac dysfunction in pressure-overloaded heart of mice. Biochem Biophys Res Commun 2006, 340:1125-1133

38. Okada K, Minamino T, Tsukamoto Y, Liao Y, Tsukamoto O, Takashima S, Hirata A, Fujita M, Nagamachi Y, Nakatani T, Yutani C, Ozawa K, Ogawa S, Tomoike H, Hori M, Kitakaze M: Prolonged endoplasmic reticulum stress in hypertrophic and failing heart after aortic constriction: possible contribution of endoplasmic reticulum stress to cardiac myocyte apoptosis. Circulation 2004, 110:705-712

39. Bulteau AL, Lundberg KC, Humphries KM, Sadek HA, Szweda PA, Friguet B, Szweda LI: Oxidative modification and inactivation of the proteasome during coronary occlusion/reperfusion. J Biol Chem 2001, 276:30057-30063

40. Divald A, Powell SR: Proteasome mediates removal of proteins oxidized during myocardial ischemia. Free Radic Biol Med 2006, 40:156-164

41. Fu HY, Minamino T, Tsukamoto O, Sawada T, Asai M, Kato H, Asano Y, Fujita M, Takashima S, Hori M, Kitakaze M: Overexpression of endoplasmic reticulum-resident chaperone attenuates cardiomyocyte death induced by proteasome inhibition. Cardiovasc Res 2008, 79:600-610

42. Palumbo A, Gay F, Bringhen S, Falcone A, Pescosta N, Callea V Caravita T, Morabito F, Magarotto V, Ruggeri M, Avonto I, Musto P, Cascavilla N, Bruno B, Boccadoro M: Bortezomib, doxorubicin and dexamethasone in advanced multiple myeloma. Ann Oncol 2008, 19:1160-1165 